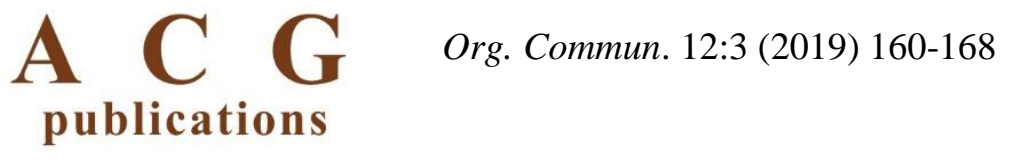

\title{
organic
} communications

\section{A Calix[4]arene-tren modified electrode for determination of Lead ions in aqueous solution}

\author{
Mustafa Baris Kocer ${ }^{1}$, Zehra Ozden Erdogan ${ }^{1}$, Mehmet Oguz ${ }^{1,2}$, \\ Semahat Kucukkolbasi ${ }^{1}$ and Mustafa Yilmaz ${ }^{1 *}$
}

\author{
${ }^{1}$ Faculty of Science, Selcuk University, Department of Chemistry, 42075, Konya, Türkiye \\ ${ }^{2}$ Department of Advanced Materials and Nanotechnology, Selcuk University, 42075 Konya, Türkiye
}

(Received July 11, 2019; Revised August 19, 2019; Accepted August 21, 2019)

\begin{abstract}
In this study, a simple and sensitive electrochemical sensor based on Calix[4]arene-tren (Calix-tren) modified glassy carbon (GC) electrode was developed for the determination of $\mathrm{Pb}$ (II) ions. Electrochemical behavior of Calix-tren modified electrodes were investigated by using cyclic voltammetry (CV) and electrochemical impedance spectroscopy (EIS). The results indicate that Calix-tren modified GC electrode provides good electron transmission pathway than bare GC electrode. The amount of $\mathrm{Pb}$ (II) was determined by differential pulse anodic stripping voltammetric analysis as a sensitive detection technique. The experimental parameters such as $\mathrm{pH}$, deposition time and deposition potential were optimized. The optimum $\mathrm{pH}$ value was selected as 7.0. The effect of deposition potential and deposition time on the peak current was tested and the optimum values were chosen as -1.2 $\mathrm{V}$ and $120 \mathrm{~s}$, respectively. Under the optimal conditions, the working range of the developed sensor was determined as $0.48-2.31 \mu \mathrm{M}$, limit of detection (LOD) was $0.11 \mu \mathrm{M}$ and the RSD obtained in the reproducibility study was $2.78 \%$. It was also found that the developed method could be used in the determination of $\mathrm{Pb}$ (II) ions in real samples with satisfactory results.
\end{abstract}

Keywords: Calix[4]arene; electrochemical sensor; Pb (II). (C) 2019 ACG Publications. All rights reserved.

\section{Introduction}

The heavy metals are toxic and poisonous at low concentrations. As trace elements, some heavy metals are required to maintain the metabolism of the human body. However, higher concentrations may lead to poisoning. Heavy metal ions pose a harmful risk to the ecological environment and public health due to their high toxicity, accumulation effect in living organisms and non-biodegradable properties ${ }^{1,2}$.

$\mathrm{The} \mathrm{Pb}$ (II) ion is a representative of heavy metal ions commonly found in the environment. Despite of its lethal and toxicity effects which are known for several centuries, lead is an environmentally important chemical element. The exposure to lead ions through contamination of food, cosmetics and cigarette smoking is not safe for humans. The presence of heavy metal ions, such as $\mathrm{Pb}$ (II) in the environment at causes health related problems like anemia, kidney damage, a disorder of the blood, memory loss, muscle paralysis ${ }^{3}$. Hence, it is increasingly important and necessary for the health of human beings to develop analytical methods that enable a fast, selective, sensitive, and convenient determination of $\mathrm{Pb}$ (II) in soil, drinking water and biosystem. Some of the approaches included conventional methods such as atomic absorption spectroscopy (AAS) and gas chromatography-mass spectrometry. However, these methods have some disadvantages that limit their effectiveness, such as cost, time-consuming, and the need for early pretreatment procedures.

The role of macrocycles for selectivity of heavy metal ions in electrochemistry has been highlighted in many recent reviews. Over the past several years, calix[n]arenes that are members of

\footnotetext{
* Corresponding author: E Mail: myilmaz42@yahoo.com 
Kocer et al., Org. Commun. (2019) 12:3 160-168

synthetic macrocycles have attracted major attention from the sensor technology community owing to their preorganized conformational features ${ }^{4}$. Calix[n]arenes are synthesized through base catalyzed electrophilic aromatic substitutions via condensation of p-tertbutyl phenols with formaldehyde a significant group of building blocks. These cyclic supramolecules are easily available on a great scale and have almost unlimited possibilities for different chemical modification ${ }^{5}$. Moreover, the calix[n]arene skeleton can be variously derivatized at both the upper and lower rim to gain a variety of structures with a large range of applications in different areas in electrochemistry. In recent years, calixarenes have gained important attention organized properties for the synthesis of different calixarene derivatives with the suitable complexing gap to recognize various species of heavy metal ions ${ }^{6,7}$.

Herein, by utilizing the unique properties of calixarenes, we have developed an electrochemical biosensor for the determination of $\mathrm{Pb}$ (II) in aqueous solutions.

\section{Experimental}

\subsection{Chemicals and apparatus}

Potassium chloride $(\mathrm{KCl})$, ethylene diamine (EDA), 1-ethyl-3-(3-dimethylaminopropyl) carbodiimide (EDC), N-hydroxy succinimide (NHS), potassium ferricyanide, dimethyl sulfoxide (DMSO) were purchased from Sigma Aldrich. All electrochemical studies were performed with IVIUM electrochemical analyzer (Ivium Technologies, Netherlands). A conventional three electrode system equipped with a modified glassy carbon electrode (GCE) as the working electrode, a $\mathrm{Ag} / \mathrm{AgCl}$ electrode (BAS MF 2052) as the reference electrode, and a platinum wire (BAS MW 1034) as the auxiliary electrode, was used for all electrochemical measurements.

The $\mathrm{pH}$ values of solutions were measured with Orion $410 \mathrm{~A}+\mathrm{pH}$ meter and ORION combined $\mathrm{pH}$ electrode. All aqueous solutions were prepared with distillated water obtained from Millipore MilliQ Plus water purification system. ${ }^{1} \mathrm{H}$ NMR spectra were referenced totetramethylsilane (TMS) at 0.00 $\mathrm{ppm}$ as the internal standard solutionand recorded on a Varian $400 \mathrm{MHz}$ spectrometer at room temperature $\left(25 \pm 1{ }^{\circ} \mathrm{C}\right)$.

\subsection{Synthesis of Calix[4]arene-tren derivative}

The calix[4]arene derivatives (1-3) were synthesized according to reported methods ${ }^{8,9}$. Calixtren (3): Yield $91 \%$; ${ }^{1} \mathrm{H}-\mathrm{NMR}\left(400 \mathrm{MHz}, \mathrm{CDCl}_{3}\right)$ : $\delta(\mathrm{ppm}) 8.39$ (t, 2H, NH), $7.25(\mathrm{~d}, 4 \mathrm{H}, \mathrm{ArH}), 6.87$ (d, 4H, ArH), 4.59 (s, 4H, OCH $)_{2}, 4.29$ (d, J=13.3 Hz, 4H, $\left.\mathrm{ArCH}_{2} \mathrm{Ar}\right), 3.67$ (m, 4H, $\left.\mathrm{HNCH}_{2}\right), 3.50$ (d, $\left.J=13.3 \mathrm{~Hz}, 4 \mathrm{H}, \mathrm{ArCH}_{2} \mathrm{Ar}\right), 2.81\left(\mathrm{~m}, 6 \mathrm{H}, \mathrm{NCH}_{2}\right.$ and $\left.\mathrm{HNCH}_{2}\right), 2.51\left(\mathrm{t}, 2 \mathrm{H}, \mathrm{NCH}_{2}\right), 1.38\left(\mathrm{~s}, 18 \mathrm{H} \mathrm{C}\left(\mathrm{CH}_{3}\right)_{3}\right)$, $1.07\left(\mathrm{~s}, 18 \mathrm{H}, \mathrm{C}\left(\mathrm{CH}_{3}\right)_{3}\right)$.

\subsection{Preparation and characterization of modified electrodes}

Before modification, the bare glassy carbon electrode (GCE) surface was polished with alumina slurry, then rinsed throughly with distillated water, followed by ultrasonication in acetonitrile and distilled water for $5 \mathrm{~min}$ respectively. After the cleaning process, the GCE was dried in air. Modified electrodes were prepared according to previous study ${ }^{1}$. For this purpose, the modifier solution was prepared by mixing $0.2 \mathrm{mg} / \mathrm{mL}$ Calix-tren in chloroform, $10.0 \mathrm{mM}$ EDA, $2.0 \mathrm{mM}$ EDC and $5.0 \mathrm{mM}$ NHS in DMSO, respectively. Then, the bare GCE was immersed in this solution for $1 \mathrm{~h}$. After the modification, the modified electrode was allowed to dry in air. The modification scheme is shown in Figure 2. 


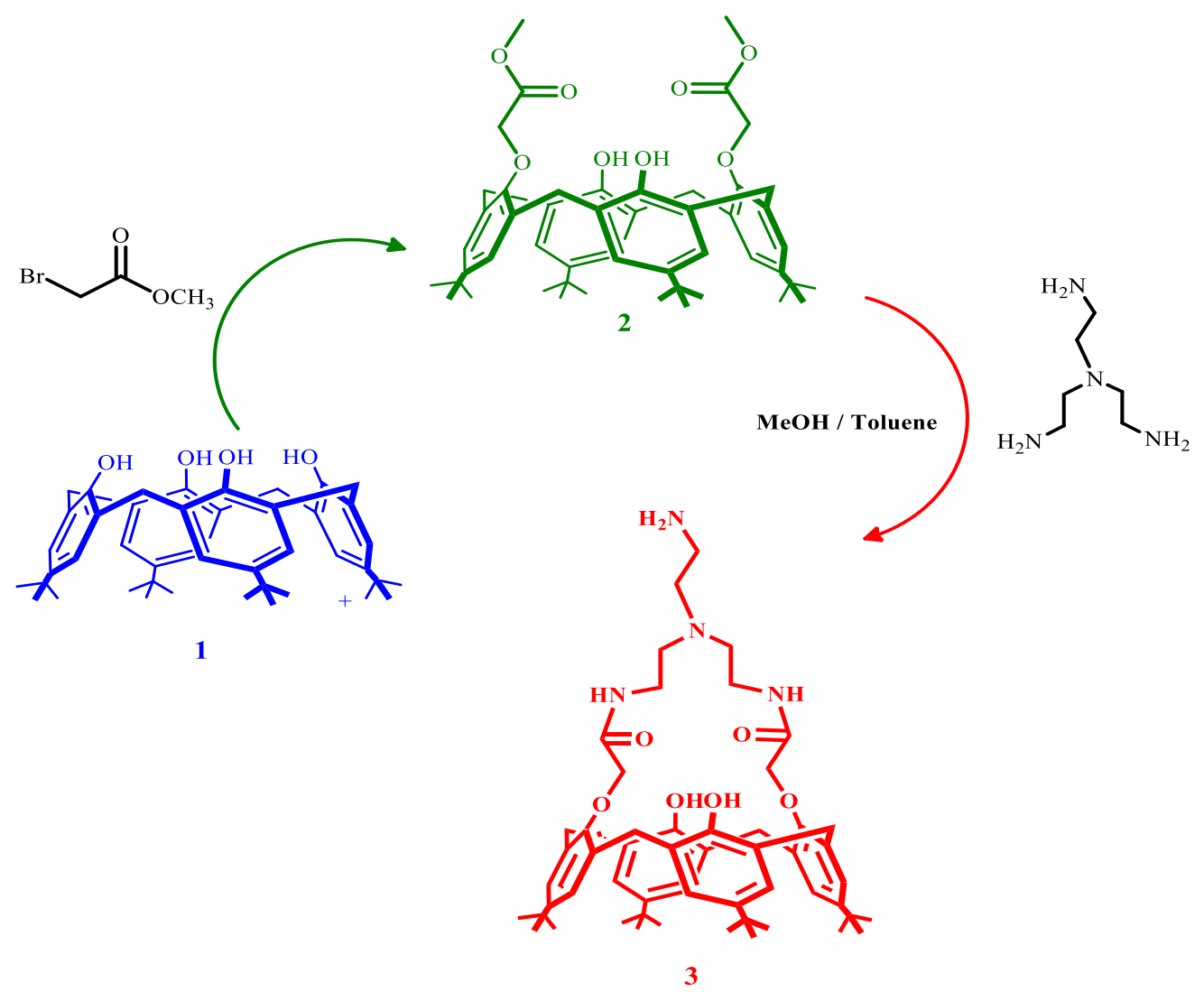

Figure 1. Synthesis of calix[4]arene-tren derivative (3)

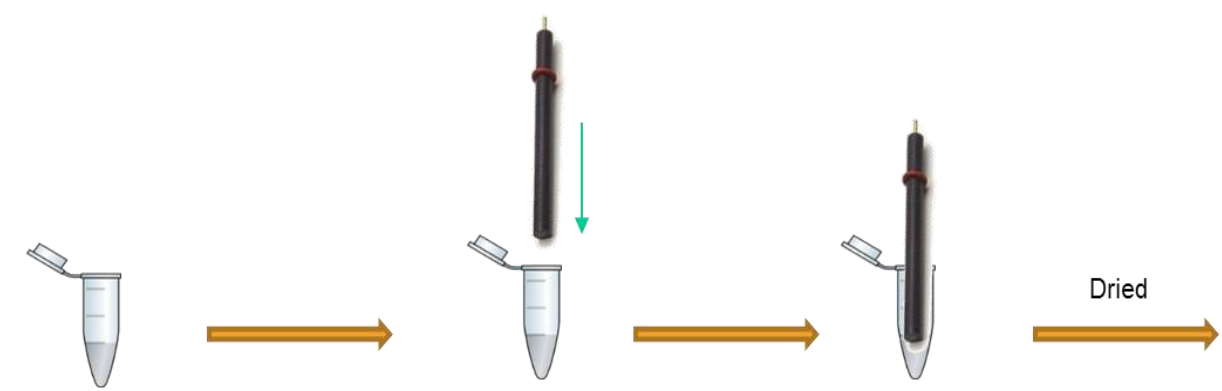

Modifier solution $\quad>$ GCE was immersed in modifier solution for $1 \mathrm{~h}$

GCE/Calix-tren

Figure 2. Scheme of the modification process 3.

The proposed binding interaction of GC/Calix-tren electrode with $\mathrm{Pb}$ (II) ion is shown in Figure 

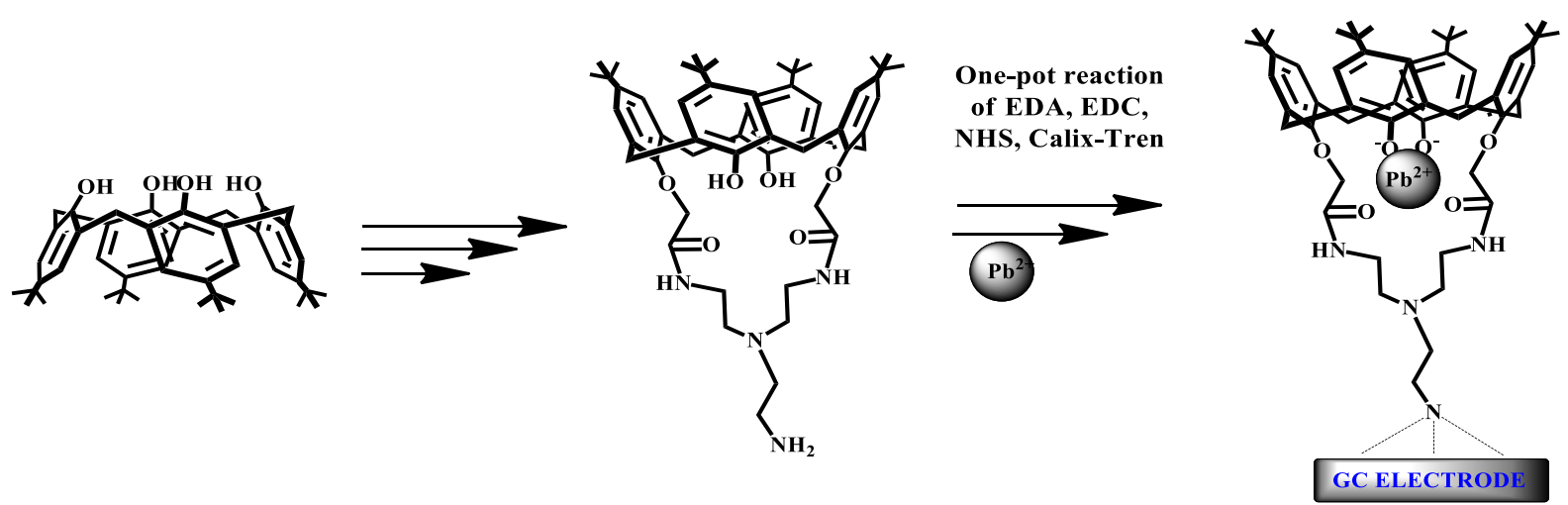

Figure 3. Proposed binding interaction of GC/Calix-tren electrode with $\mathrm{Pb}$ (II) ion

\subsection{Electrochemical procedure}

Electrochemical properties of GC/Calix-tren and GC electrode surface were characterized by $\mathrm{CV}$ and EIS measurements in $5.0 \mathrm{mM} \mathrm{Fe}(\mathrm{CN}) 6^{3-14-}$ solution containing $0.1 \mathrm{M} \mathrm{KCl}$. Surface characterizations of the prepared electrodes were examined using Scanning Electron Microscopy (SEM) technique. Under the optimum conditions, current response of the GCE/Calix-tren electrode was measured by differential pulse anodic stripping voltammetry (DPASV) ${ }^{10}$. All measurements were carried out in $\mathrm{pH}$ 7.0 0.1 M potassium chloride and at room temperature.

The performance of the newly modified glassy carbon electrode (GCE/Calix-tren) is based on the deposition of $\mathrm{Pb}$ (II) from aqueous solution onto the surface of the modified electrode by forming complexes with the modifier. The electrochemical performance of the metal ion on the glassy carbon electrode modified with Calix-tren was explored with respect to the effect on the stripping parameter. Lastly, a calibration curve was plotted under optimized parameters.

The possible steps are explicated below with the optimized experimental values, the likely phases are clarified under ("aqueous" or "surface" subscript means the compound is in aqueous solution or on the electrode surface, respectively):

Deposition of $\mathrm{Pb}$ (II) ${ }^{11}$

$\mathrm{Pb}$ (II) ${ }_{\text {(aqueous) }}+(\text { Calix-tren) })_{\text {(surface) }} \rightarrow\left[\mathrm{Pb}\right.$ (II) $-(\text { Calix-tren) }]_{\text {(surface) }}$

Reduction of accumulated $\mathrm{Pb}$ (II)

$\left[\mathrm{M}^{2+}-(\text { Calix-tren })\right]_{\text {(surface })}+2 \mathrm{e}^{-} \rightarrow\left[\mathrm{M}^{0}-(\text { Calix-tren })\right]_{\text {(surface) }}($ at $-1.2 \mathrm{~V})$

Stripping of reduced $\mathrm{Pb}$ (II)

$\left[\mathrm{M}^{0}-(\text { Calix-tren })\right]_{\text {(surface) }} \rightarrow \mathrm{M}^{2+}{ }_{\text {(aqueous) }}+(\text { Calix-tren })_{\text {(surface) }}+2 \mathrm{e}^{-}($scan from -1.5 to $-1.0 \mathrm{~V})$

\section{Results and Discussion}

\subsection{Characterization of Calix[4]arene-tren} (Figure S1).

The structure of the synthesized calix-tren derivative ${ }^{8}$ was confirmed by ${ }^{1} \mathrm{H}$ NMR analysis 

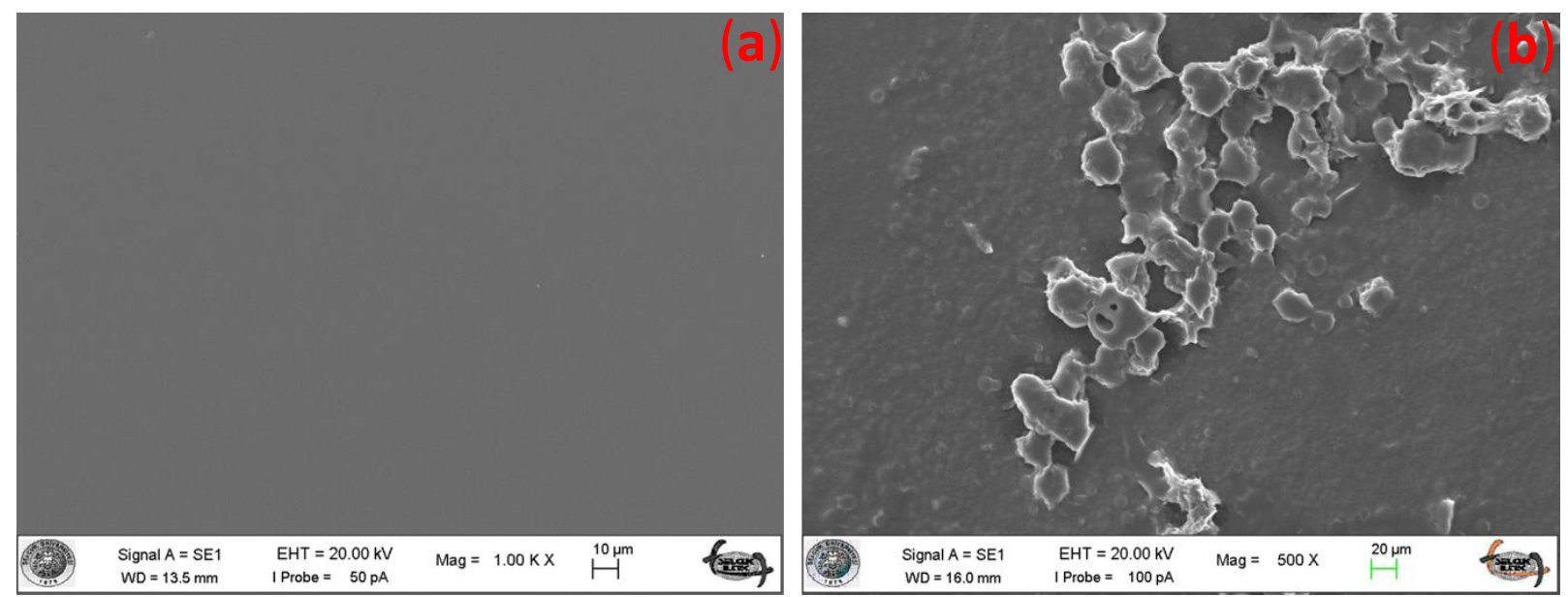

Figure 4. SEM micrographs of the BGCE (a), GCE/Calix-tren (b)

The surface morphologies of the bare GCE and GCE/Calix-tren were investigated using SEM. SEM micrographs of bare GCE and GCE/Calix-tren are shown in Figure 4. The surface morphology of bare GCE (Figure 4.(a)) is different from than that of GCE/Calix-tren (Figure 4.(b)). As seen in Figure 4 (a), bare GCE exhibits a more uniform and smooth structure. After the modification, well dispersed Calix-tren were observed onto BGCE (Figure 4.(b)).

Ferro-ferricyanide ion $\left(\mathrm{Fe}(\mathrm{CN}) 6^{3-/ 4-}\right.$ ) was used as redox probe to investigate the electron transfer properties of bare GCE and modified GCE. Cyclic voltammetry of the redox probes such as ferrocyanide system is a convenient and useful tool to investigate the characterization of modified electrode surfaces ${ }^{12}$. Figure 5 shows the cyclic voltammograms of the bare GCE and GCE/Calix-tren electrodes at a scan rate of $100 \mathrm{mV} \mathrm{s}^{-1}$ in redox probe solution including $0.1 \mathrm{M} \mathrm{KCl}$. When Calix-tren was modified on the electrode, the redox current decreased. This suggested that Calix-tren acted as the blocking layer for electron and mass transfer that hinders the diffusion of ferricyanide toward the electron surface, which obviously also prove that Calix-tren successfully immobilized on the GCE surface.

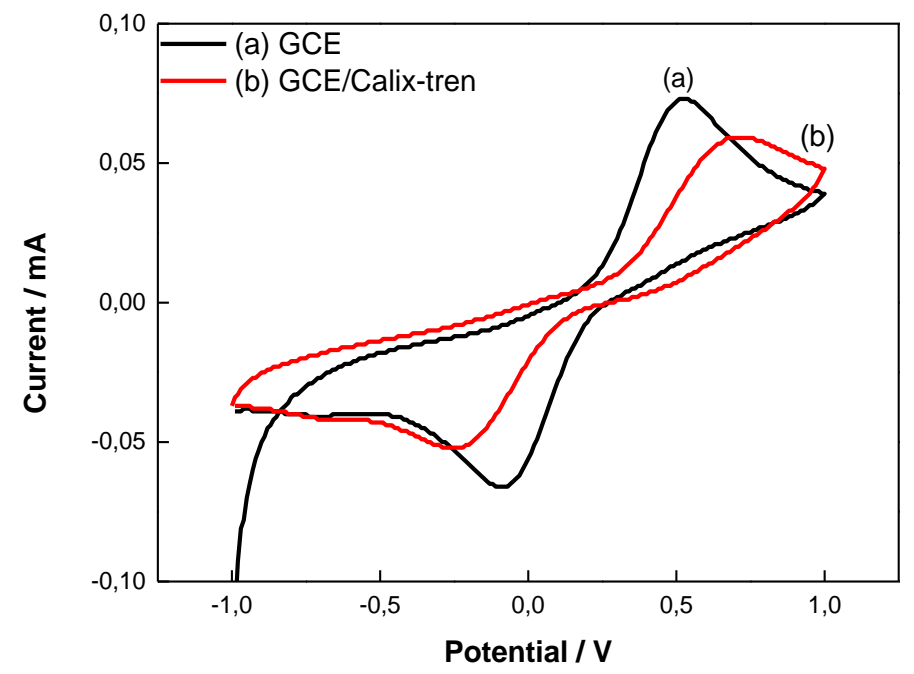

Figure 5. CVs of GCE (a), GCE/Calix-tren (b) electrode at scan rate of $100 \mathrm{mV} \mathrm{s}^{-1}$ in $0.1 \mathrm{M} \mathrm{KCl}$ containing $5.0 \mathrm{mM} \mathrm{Fe}(\mathrm{CN})_{6}^{3-/ 4-}$.

The capability of electron transfer on these electrodes was also investigated by EIS. EIS is an effective method to monitor the impedance changes of the electrode surface during the fabrication 
Kocer et al., Org. Commun. (2019) 12:3 160-168

process. Figure 6 shows the Nyquist plot of EIS at GCE and GCE/Calix-tren. It can be seen that a small well-defined semi-circle was obtained at the bare GCE, indicating small interface electron resistance $\left(R_{\mathrm{ct}}\right)$. And, the $R_{\mathrm{ct}}$ increased further remarkably after Calix-tren was immobilized on the GCE. This result showed that Calix-tren was successfully immobilized on the GCE surface.

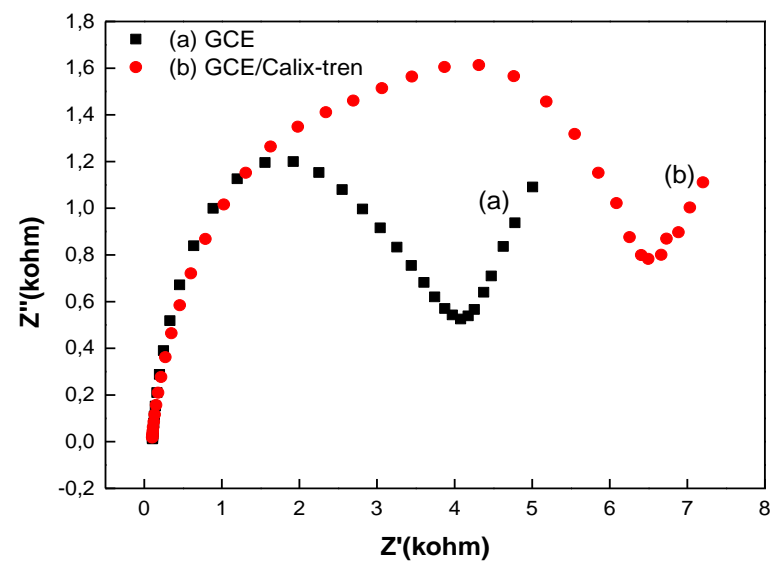

Figure 6. The Nyquist plots of (a) GCE, (b) GCE/Calix-tren in $0.1 \mathrm{M} \mathrm{KCl}$ containing $5.0 \mathrm{mM}$ $\mathrm{Fe}(\mathrm{CN})_{6}^{3-/ 4}$

\subsection{Optimization of experimental conditions}

In order to determine optimum experimental conditions, the effect of $\mathrm{pH}$, working potential and deposition time were investigated.
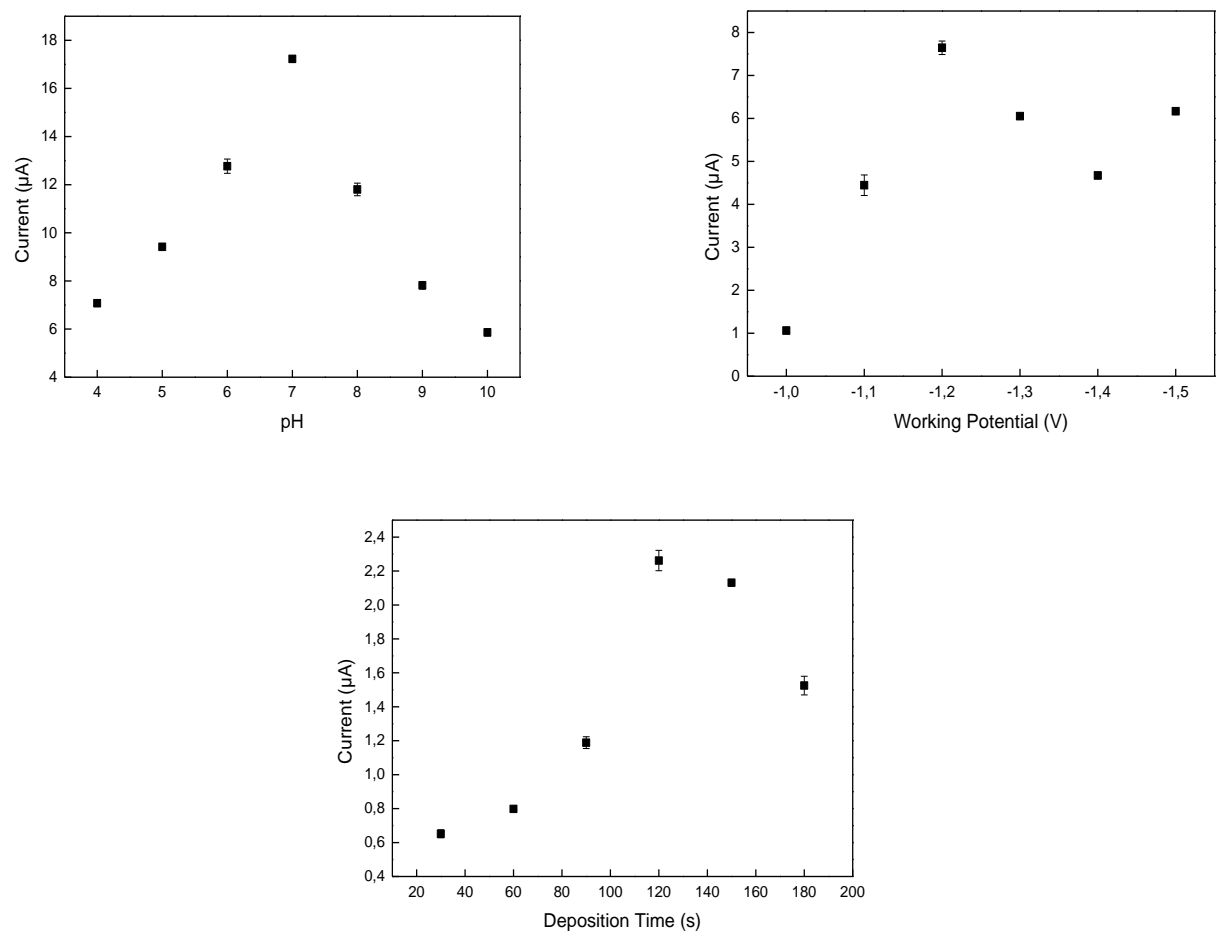

Figure 7. The effect of $\mathrm{pH}$, working potential and deposition time on the response on the response of GCE/Calix-tren 
The effect of $\mathrm{pH}$ on the currrent response was investigated at a range of 4.0-10.0. The peak current was increased from $\mathrm{pH} 4.0$ to 7.0 and decreased after $\mathrm{pH} 7.0$ and maximum peak current was obtained at $\mathrm{pH}$ 7.0.

Deposition potential is another importance factor to effect the performance of sensor. The effect of deposition potential on the peak current was tested at a range of (-1.0) - (-1.5) V. As the highest current was obtained with $-1.2 \mathrm{~V}$, this potential was used for further experiments.

The effect of deposition time on the peak current was also examined in the range between 30 $180 \mathrm{~s}$ and $120 \mathrm{~s}$ was chosen as an optimum value.

\subsection{Analytical performance of the developed sensor}

Differential pulse anodic stripping voltammetry technique was chosen to estimate the linear range, limit of detection and limit of quantification, because of its excellent current sensitivity and selectivity in a low background. Under the optimum conditions, DPASV response for different concentration of $\mathrm{Pb}$ (II) are shown in Figure 8.

The peak currents linearly proportional to $\mathrm{Pb}$ (II) concentration over the range of $0.48-2.31 \mu \mathrm{M}$. The correlation equation for determination of $\mathrm{Pb}$ (II) :

$$
\mathrm{I}_{\mathrm{p}}(\mu \mathrm{A})=231.67 \mathrm{C}_{\mathrm{Pb}(\mathrm{II})}+105.48\left(\mathrm{R}^{2}=0,9943\right)
$$

The limit of detection (LOD) and the limit of quantification (LOQ) from the calibration curve were found to be $0.11 \mu \mathrm{M}$ and $0.36 \mu \mathrm{M}$, respectively. LOD and LOQ were calculated using the following equations ${ }^{13]}$ :

$$
\begin{aligned}
& \mathrm{LOD}=3 \mathrm{~s} / \mathrm{m} \\
& \mathrm{LOQ}=10 \mathrm{~s} / \mathrm{m}
\end{aligned}
$$

Where $s$ is the standard deviation of the current of the lowest concentration of the linearity range, $m$ is the slope of the related calibration curve.

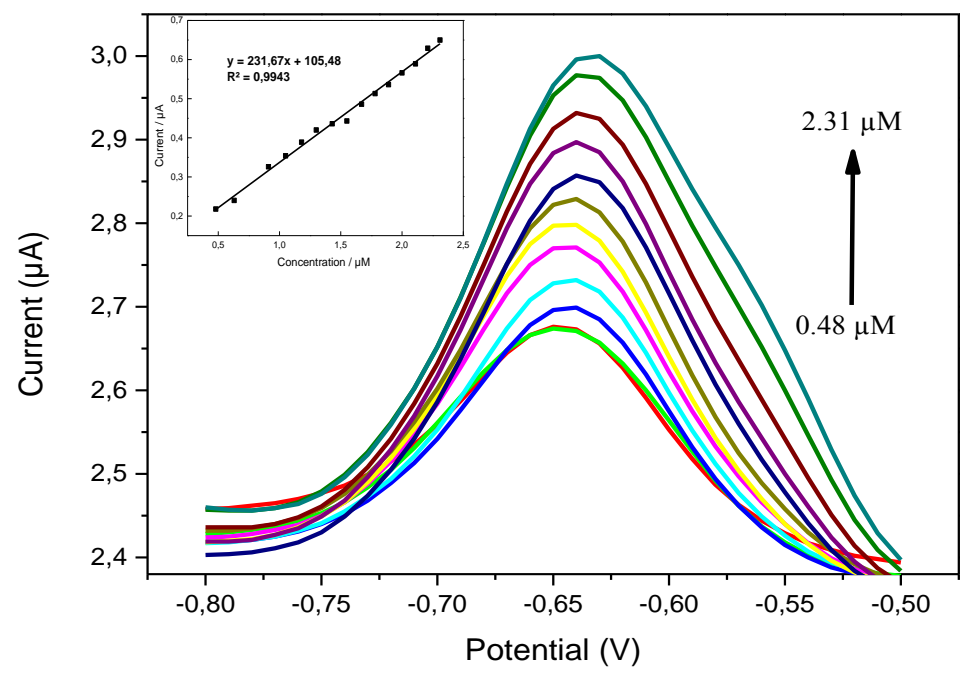

Figure 8. Differential pulse voltammograms of the GCE/Calix-tren electrode in $0.10 \mathrm{M} \mathrm{KCl}(\mathrm{pH} 7.0)$ containing different $\mathrm{Pb}$ (II) concentrations, Inset: Calibration plots of GCE/Calix-tren

The repeatability for the same electrode was calculated from the relative standard deviation (RSD) of lead currents and it was found to be $3.71 \%(n=7)$. 


\section{Kocer et al., Org. Commun. (2019) 12:3 160-168}

The reproducibility was calculated using three different electrodes prepared in the same way. The RSD of sensitivities of three electrodes was $2.78 \%$. The results show that the reproducibility and repeatability of the prepared sensor is acceptable level.

\subsection{Interference studies}

In order to measure of selectivity of the sensor, the effect of some interfering substances such as $\mathrm{Cd}$ (II), $\mathrm{Co}$ (II), $\mathrm{Cu}$ (II), $\mathrm{Fe}$ (II), Ni (II) and $\mathrm{Zn}$ (II) was examined. Figure 9 shows the comparison between the current response of the control which is a solution containing $1 \mathrm{mM} \mathrm{Pb}$ (II) in $\mathrm{KCl}$ solution with the current magnitude of the control in the presence of different metal ions.

Compared with the current response change of sensor to $\mathrm{Pb}(\mathrm{II})$, the relative current response changes for $\mathrm{Cd}$ (II), $\mathrm{Co}$ (II), $\mathrm{Cu}$ (II), Fe (II), Ni (II) and Zn (II) were found to be as $-1.0 \%, 4.20 \%, 4.70 \%$, $-3.10 \%$ and $8.20 \%$, respectively. When Fig. 9 is examined, it is concluded that the interference effect of each species is quite low and it did not significantly affect the $\mathrm{Pb}$ (II) determination.

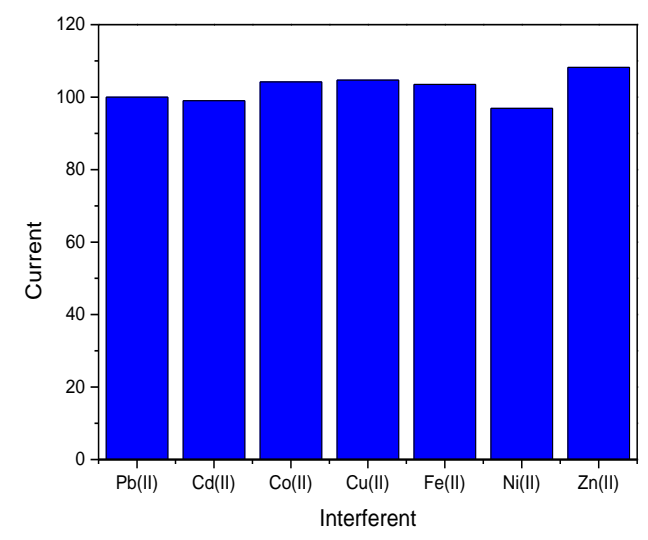

Figure 9. The effect of the interfering substances on electrochemical responces of $\mathrm{Pb}$ (II) at GCE/Calixtren

\subsection{Real sample analysis}

To demonstrate the applicability of the sensor in practical analysis, it was used to detect $\mathrm{Pb}$ (II) in wastewater. The standard addition method was used for the analysis of prepared samples. In this method, additions of standard $\mathrm{Pb}$ (II) solution were made to the waste water, and a multiple addition calibration curve was obtained.

Table 1. Determination of $\mathrm{Pb}$ (II) in waste water

\begin{tabular}{ccc}
\hline Sample & Analyte & Found $(\mathbf{m g} / \mathbf{L}) \pm \mathbf{S D}^{\mathbf{a}}$ \\
\hline Waste water & $\mathrm{Pb}(\mathrm{II})$ & $0.362+0.004$ \\
\hline
\end{tabular}

a Average of 5 determinations

As can be seen in Table 1, the amount of $\mathrm{Pb}$ (II) in waste water was found to be $0.362+0.004$ $\mathrm{mg} / \mathrm{L}$. The obtained results show that the proposed sensor provided a new electrochemical sensing approach for the determination of $\mathrm{Pb}$ (II) in environment residues.

\section{Conclusion}

The calixarene modified electrode (calix-tren) for the detection of $\mathrm{Pb}$ (II) was sucessfully prepared. The working range of the developed electrochemical sensor was determined as 0.48-2.31 $\mu \mathrm{M}$, 
limit of detection (LOD) was $0.11 \mu \mathrm{M}$ and the RSD obtained in the reproducibility study was $2.78 \%$. Calix-tren was able to retain its selectivity for $\mathrm{Pb}$ (II) response in presence of $\mathrm{Cd}$ (II), $\mathrm{Co}$ (II), $\mathrm{Cu}$ (II), $\mathrm{Fe}$ (II), Ni (II) and $\mathrm{Zn}$ (II) ions. It was also found that the proposed electrochemical sensor possessed great advantages such as low cost, good selectivity, good reproducibility and could be used in the determination of $\mathrm{Pb}$ (II) ions in aqueous solution with satisfying results.

\section{ORCID}

Mustafa Baris Kocer: 0000-0001-8439-1966

Zehra Ozden Erdogan: 0000-0002-1687-973X

Mehmet Oguz: 0000-0002-3999-620X

Semahat Kucukkolbasi: 0000-0002-5129-5385

Mustafa Yilmaz: 0000-0003-2904-160X

\section{References}

[1] Nur Abdul Aziz, S.F.; Zawawi, R.; Alang Ahmad, S.A. An Electrochemical sensing platform for the detection of lead ions based on dicarboxyl-Calix [4] arene. Electroanalysis 2018, 30(3), 533-542.

[2] Schock, M.R. Causes of temporal variability of lead in domestic plumbing systems. Environment. Monitor. Assesment 1990, 15(1), 59-82.

[3] Fu, F.; Wang, Q. Removal of heavy metal ions from wastewaters: a review. J.Environment. Man. 2011, 92(3), 407-418.

[4] Yilmaz, M.; Sayin, S. Calixarenes in organo and biomimetic catalysis, in Calixarenes and Beyond. Springer 2016, 719-742.

[5] Bhatti, A.A.; Oguz, M.; Yilmaz, M. One-pot synthesis of Fe3O4@ Chitosan-pSDCalix hybrid nanomaterial for the detection and removal of $\mathrm{Hg}^{2+}$ ion from aqueous media. Appl. Surface Sci. 2018, 434, 1217-1223.

[6] Sulak, M.; Kursunlu, A. N.; Girgin, B.; Ozen Karakus, O.; Guler, E. A highly selective fluorescent sensor for mercury (II) ion based on Bodipy and Calix [4] arene bearing triazolenaphthylene groups; synthesis and photophysical investigations. J. Photochem. Photobiol. A: Chemistry 2017, 349, 129-137.

[7] Yilmaz, M.; Karanastasis, A., A.; Chatziathanasiadou, M., V.; Oguz, M.; Kougioumtzi, A.; Clemente, N.; Kellici, T. K.; Zafeiropoulos, N., E.; Avgeropoulos, A.; Mavromoustakos, T.; Dianzani, U.; Karakurt, S.; Tzakos, A. G. Inclusion of quercetin in gold nanoparticles decorated with supramolecular hosts amplifies its tumor targeting properties. ACS Appl. Bio Materials 2019, 27, 2715-2725.

[8] Oguz, M.; Bhatti, A. A.; Karakurt, S.; Aktas, M.; Yilmaz, M. New water soluble $\mathrm{Hg}^{2+}$ selective fluorescent calix [4] arenes: Synthesis and application in living cells imaging. Spectrochim. Acta Part A: Mol. Biomol. Spectr. 2017, 171, 340-345.

[9] Gutsche, C.D.; Muthukrishnan, R. Calixarenes. 1. Analysis of the product mixtures produced by the basecatalyzed condensation of formaldehyde with para-substituted phenols. J. Org. Chem. 1978, 43(25), 49054906.

[10] Kucukkolbasi, S.; Temur, O.; Kara, H.; Khaskheli, A. R. Monitoring of Zn(II), Cd(II), Pb(II) and Cu(II) during refining of some vegetable oils using differential pulse anodic stripping voltammetry. Food Anal. Meth. 2014, 7(4), 872-878.

[11] Kucukkolbasi, S.; Erdogan, Z. O.; Barek, J.; Sahin, M.; Kocak, N. A novel chitosan nanoparticle-schiff base modified carbon paste electrode as a sensor for the determination of $\mathrm{Pb}$ (II) in waste water. Int. J. Electrochem. Sci. 2013, 8, 2164-2181.

[12] Liu, X.; Li, Y.; Liang. J.; Zhu, W.; Xu, J.; Su, R.; Yuan, L.; Sun, C. Aptamer contained triple-helix molecular switch for rapid fluorescent sensing of acetamiprid. Talanta 2016, 160, 99-105.

[13] Tig, G. A.; Gunendi, G.; Bolelli, T. E.; Yalcin, I.; Pekyardimci, S. Study on interaction between the 2-(2phenylethyl)-5-methylbenzimidazole and dsDNA using glassy carbon electrode modified with poly-3amino-1, 2, 4-triazole-5-thiol. J. Electroanal. Chem. 2016, 776, 9-17.

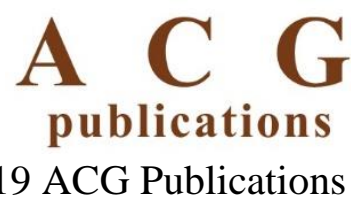

